- Creep and fracture behaviour of Nickel-Aluminium alloy with Aluminium con- . centration of $7.13 \%$ was investigated at $1073 \mathrm{~K}$ over a range of stresses: from 40 to $115 \mathrm{MPa}$. The alloy consists of solid solution matrix strengthened by $\gamma^{\prime}(\mathrm{Ni} 3 \mathrm{AL})$ particles. High precision constant stress creep curves have been obtained and analysed in terms of creep rate and fracture life.

Over most of the transient and steady creep curve, the strain at any instant can be described accurately as :

$$
\varepsilon=\varepsilon_{0}+\varepsilon_{p}\left(1-e^{-m t}\right)+\dot{\varepsilon}_{s} t
$$

where $\varepsilon_{o}$ is the instantaneous strain on loading, $\varepsilon_{p}$ the total transient strain, $\dot{\varepsilon}_{\mathrm{s}}$ the steady-creep rate, and $\mathrm{m}$ a constant relating to the rate of exhausion of transient creep.

Analysis of the tertiary creep curves in terms of particle coarsening has been made and compared with the experimental results and also with different equations based on strain dependent damage. The results of the analysis combined with the scanning electron microscope observations of the frac- tured surfaces have shown that damage in the form of intergranular cavita- : tion and cracking is the most probable mechanism responsible for creep frac: ture in this case.

\title{
INTRODUCTION
}

For a number of materials $|1-6|$, it has been shown that the time dependence of the true strain over most of transient and steady state creep can be well represented by the Garofalo $|1|$ equation :

$$
\varepsilon=\varepsilon_{0}+\varepsilon_{p}\left(1-e^{-m t}\right)+\dot{\varepsilon}_{s} t
$$

\section{*Associate Professor}

Mechanical Engineering Department, AL-Azhar University

Nasr City, Cairo, Egypt. 

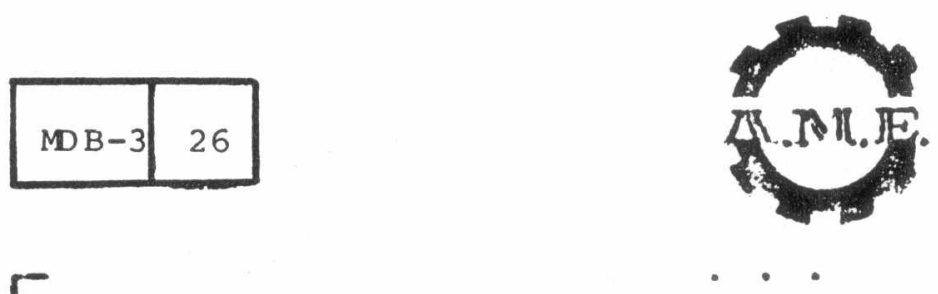

SECOND A.M.E. CONFERENCE

6 - 8 May 1986 , Cairo

r

where $\varepsilon_{0}$ is the instantaneous strain on loading, $\varepsilon_{\mathrm{p}}$ the total transient strain, $m$ a constant relating to the rate of exaustion of transient creep and $\dot{\varepsilon}_{\mathbf{S}}$ is the steady creep rate.

For the majority of strain in tertiary, the strain time relationship has been shown $|5,7,8|$ to be given by :

$$
\varepsilon=\dot{\varepsilon}_{s} t+\varepsilon_{L} \cdot e^{P\left(t-t_{t}\right)}
$$

where $\varepsilon_{L}$ and $P$ are constants and $t_{t}$ is the time to the onset of tertiary creep. Howevor, the accuracy of this relationship in predicting the true shape of the tertiary creep curve has been tested by silcock|9|. It was shown that in many Ferritic steels particle coarsening continualiy reduces: the creep strength and consequently give a tertiary type curve different of : that described by the exponential relationship. On the other hand recent study $|10|$ of tertiary creep in Ni/10\% CO alloy hardened by $\gamma^{\prime}$-particles has shown that the time dependence of creep strain, $\varepsilon_{t}$, in the early stages of tertiary creep can be described by :

$$
\varepsilon_{t}=\dot{\varepsilon}_{s} t+K\left(t-t_{t}\right)^{n}
$$

where $K$ and $n$ are constants. After this intial period, $(\simeq 12$ to 188 of the total time spent in tertiary), the tertiary creep curve is very well represented by equation (2). This behaviour was similar to the creep behaviour of pure metals $|7,8|$; where tertiary creep is associated with intergranular cavitation and cracking.

The aim of the present work was to :

a- Study the creep and fracture behaviour of Ni-7.13\% AL alloy at high tem-: perature.

b- examine the applicability of the strain-time relationship describing the transient and steady state creep curve.

c- analyse the form of constant stress tertiary creep curves in terms of equations based on particle coarsening and those based on damage accumulation as a function of creep strain.

\section{EXPERIMENTAL PROCEDURE}

Ni-7.13\% AL alloy was supplied in the form of hot rolled $7 \mathrm{~mm}$ diameter rods. From these rods, specimens were machined having $21 \mathrm{~mm}$ gauge length and $3 \mathrm{~mm}$. gauge diameter. The specimens were solution-treated for 1 hour at $1323 \mathrm{~K}$ : under vacuum, followed by quenching in water path and then aged at $1073 \mathrm{~K}$ for 10 hours. This treatment resulted in a grain size of $0.18 \mathrm{~mm}$, with a uniform dispersion of Ni3 AL particles throughout the matrix solid solution. Tensile creep tests were carried out over a stress range of $40-115 \mathrm{MN} / \mathrm{m}^{2}$ at the same ageing temperature in order to a void any further precipitation during the creep test. Strains were measured by variable capacitance transducers capable of reading to $10^{-5} \mathrm{~mm}$. The specimen's temperature was maintained to $\pm 3 K$ with no detectable variation along the gauge length. 
RESULTS AND DISCUSSION

Transient and Steady Creep Curves

In agreement with several investigations $|1-6|$ the variation with $t i m e, t$, of the true strain, $\varepsilon$, during transient and steady state creep for the present alloy can be described by equation (1). For each test, the best value of the constants $\varepsilon_{0}, \varepsilon_{\mathrm{p}}, \mathrm{m}$ and $\dot{\varepsilon}_{\mathrm{s}}$, table 1 , was determined by a least square analysis method based on the graphical solution for this equation as proposed by Conway $|2|$. About 50 strain/time readings were taken during each "creep test. Over most of the transient and steady creep curve, the average :difference between the measured strain, $\varepsilon$, and the calculated value, $\varepsilon_{c}$, us-: ing the derived constants was <0.000008. However, this difference increased: progressivelly, during the intial 10-15\% of the transient stage, as $t$ approached zero as shown in Fig.l. Similar trends have been noted for other materials $|3-5|$. It has been shown that the creep rate, $\dot{\varepsilon}$, at any instant during transient and steady creep stage is related to the rate of recovery $r(=-\partial \sigma / \partial t)$ as

$$
\dot{\varepsilon}=r / h
$$

where $h(=\hat{c} \sigma / \partial \varepsilon)$ is the coefficient of strain hardening. During the intial period $(\simeq 10-15 \%)$ of transient stage, h increases rapidly and thereafter remains constant. This increase in $\mathrm{h}$ coincides with the period during which deviations from equation (1) occur.

Table 1. Stress dependence of the creep parameters

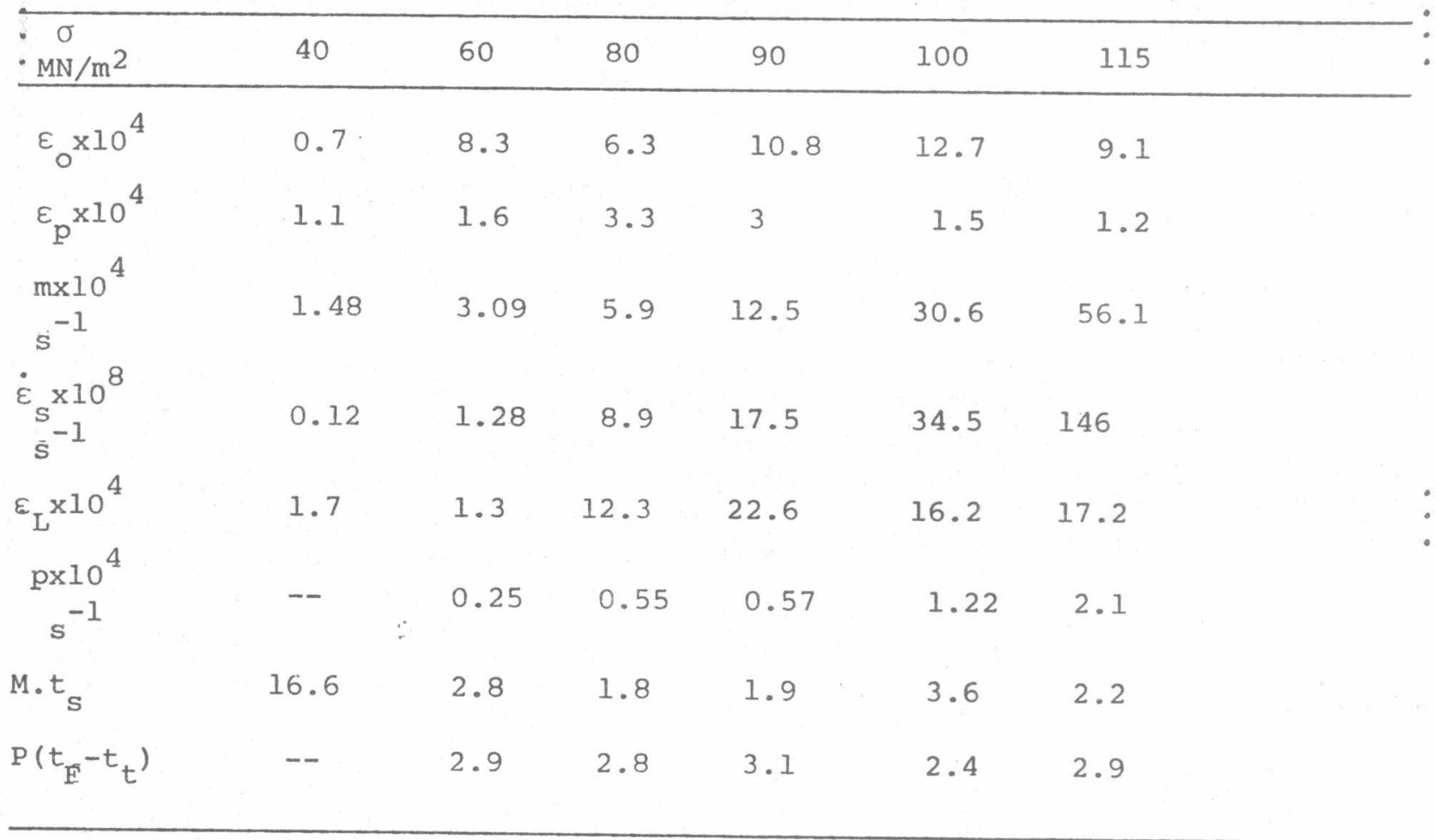




\section{Analysis of Tertiary Creep Curves}

In agreement with recent work $|10|$, the time dependence of creep strain in the early stages of tertiary creep can be accurately described by equation (3) as shown in Fig.2. However, the value of the constant $n$, in the present case, is $\simeq 1.6$ and the intial periods over which equation (3) is followed extend for up to 30-50\% of the total time in tertiary and 20-30\% of the total strain in tertiary. Following this period, the strain-time relationship could be accurately represented by equation (2). The best values of the constants $\varepsilon_{L}$ and $P$ are given in table.l over the investigated stress range. If the primary creep strain is very small compared to the total -strain, as found in the present case, then the creep rate at any instant could be calculated by differentiating equation (2) to give:

$$
\dot{\varepsilon}=\dot{\varepsilon}_{S}+\varepsilon_{L} \cdot P e^{p\left(t-t_{t}\right)}
$$

The values of $\mathrm{P}\left(t_{\mp}-t_{t}\right)$ was found to be approximately constant $\simeq 3$ irrespective of the applied stress as can been seen from table 1. Substituting the calculated $\varepsilon_{\mathrm{L}}$ and $\mathrm{P}$ values in equation (5), the predicted values of $\dot{\varepsilon} / \dot{\varepsilon}_{\mathrm{S}}$ could be drawn as a function time at each stress level. In addition, if particle coarsening is responsible for the observed acceleration in creep rate and consequently the tertiary creep behaviour, then according to silcock $|9|$ the creep rate should be predicted by :

$$
\dot{\varepsilon}=\dot{\varepsilon}_{s}\left|1+A\left(\left(t-t_{t}\right) /\left(t_{f}-t_{t}\right)\right)^{y}\right|
$$

.where $A$ and $Y$ are constants and $t_{F}$ is the time to fracture. From condi-. -tions at rupture

$$
1+A=\dot{\varepsilon}_{F} / \dot{\varepsilon}_{S}
$$

where $\dot{\varepsilon}_{F}$ is the creep rate at fracture. Putting $t_{t}=0$ and integrating equation $^{\mathrm{F}}(6)$ gives ;

$$
1+y=A \dot{\varepsilon}_{S} t_{F} /\left(\varepsilon_{F}-\dot{\varepsilon}_{S} t_{F}\right)
$$

A knowledge of $\dot{\varepsilon}_{F} / \dot{\varepsilon}_{S}$ is required beside $\varepsilon_{F}$ and $\dot{\varepsilon}_{S} t_{F}$, which is frequently constant and not $\stackrel{\mathrm{F}}{\mathrm{S}} \mathrm{E} \mathrm{S}_{\mathrm{S}} \mathrm{s}$ dependant, in order ${ }_{\mathrm{F}}$ to calculate $\dot{\varepsilon} / \dot{\varepsilon}_{\mathrm{S}}$. On the other hand, if a strain dependant damage is responsible for the observed tertiary creep behaviour, as proposed by Robotnov |1l|and not creep tests should vary with the elapsed time creep rates occuring during

$$
\dot{\varepsilon}=\dot{\varepsilon}_{s} /\left(1-\frac{t}{t_{f}}\right) n^{\prime} / \eta+1
$$

where $n^{\prime}, n$ are constants and;

$$
\frac{n^{\prime}}{n+1}=1-\dot{\varepsilon}_{s} t_{F} / \varepsilon_{F}
$$

and must therefore always be less than or equal to 1 . The correlation of the increase in creep rates as a function of $t / t_{f}$ according to the exponential relationship-equation (2), particle coarsening-equation (6), and 
\begin{tabular}{|l|l|}
\hline MD B-3 & 29 \\
\hline
\end{tabular}

$\Gamma$
SECOND A.M.E. CONFERENCE

6 - 8 May 1986 , Cairo

strain dependant damage-equation (9), is given in Fig.3 at different stress levels. For comparison, the predicted values are superimposed on the experimental results at each stress. In general, the calculated values according to the exponential equation are in better agreement with the experimental results. However, non of the considered equations gives a good and close fit to the observed relatively rapid initial increase in the creep rate in particular the equation based on particle coarsening. Therefore, it seems possible that creep damage in the form of intergranular cavitation or cracking is responsible for the observed tertiary creep behaviour in the present case. To check this possibility, scanning electron microscope examinations of both uncrept and crept specimens were made. Fig.4.a shows the -microstructure of the aged and not creep tested alloy, where a uniform dis-" persion of $\gamma^{\prime}$ - particle throughout the grains is evidently clear. Subject-: ion, of the specimen to creep testing under a stress of $90 \mathrm{mN} / \mathrm{m}^{2}$ for etra time has not resulted in a very significant particle coarsening as can be seen from Fig.4b. Further examination of the internal fractured surfaces, Fig.4c, has shown that wedge type cracks to be a prominant feature over the whole range of applied stresses. However, it was very interesting to note that some of the fractured surfaces were composed almost of adjoining yet discrete cavities on the grains facets as shown in Fig.4c (Left-hand side grain interface). Neverthless, decohesion at these grain boundaries can not be entirely ascribed to the growth and coalescence of such a small number of cavities which may have been nucleated early on in the creep life. It is possible that the single grain-facet cracks initiate other cracks along the adjacent cavitated grain boundaries.

\section{CONCLUSIONS}

1- Over most of the creep curve, the strain at any instant can be described: for $\mathrm{Ni}-7.13 \% \mathrm{Al}$ alloy by the equation

$$
\varepsilon=\varepsilon_{0}+\varepsilon_{p}\left(1-e^{-m t}\right)+\dot{\varepsilon}_{s} \cdot t
$$

However, during the first 10-15\% of the transient stage, the creep rate decreased more rapidly than is predicted by this equation.

2- The equation basedon particle coarsening of $\gamma^{\prime}$ - particles is unable to account for tertiary creep in the present case. The well known exponential expression gives a better fit to the experimental curves over $\simeq 75 \%$ of the total strain and $\simeq 60 \%$ of the total time spent in tertiary.

3- Creep damage in the form of intergranular cracking is the most probable . micro-mechanism responsible for the observed tertiary creep behaviour and fracture in $\mathrm{Ni}-7.13 \% \mathrm{AL}$ alloy.

\section{ACKNOWLEDGEMENT}

The authours wish to thank Prof. H. Cerjack for allowance to use the facilities available at the department of materials and welding technology, technical university of Graz, Austria.

REFERENCES

1. Garofalo F., "Fundamentals of Creep and Creep-Rupture in Metals", Mcmillan, New York, (1965). 


\section{\begin{tabular}{l|l|l} 
MD B-3 & 30
\end{tabular}}

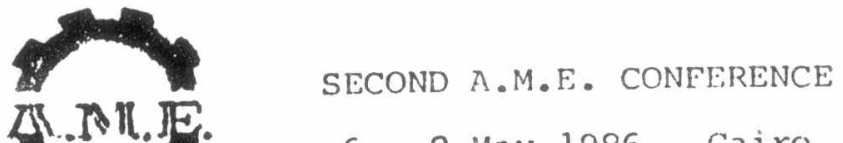

6 - 8 May 1986 , Cairo

2. Conway J.B. and Mullikin M.J., "Techniques for Analyzing Combined Firstand Second-Stage Creep Data", Trans. Met. Soc. AIME, 236, 1629-1632, (1966).

3. Sidey D. and Wilshire B., "Mechanisms of Creep and Recovery in Nimonic 80 A", Metal Science J.3, 56-60, (1969).

4. Davies P.W., Evans W.J., Williams K.R. and Wilshire B., "An Equation to represent Strain/time Relationships during High Temperature Creep", Scripta Met., 3, 671-674, (1969).

.5. Evans W.J. and Wilshire B., "The High Temperature Creep and Fracture

- Behaviour of 70-30 Alpha-Brass", Met. Transactions, 1, 2133-2139, (1970) :

6. Abdou M.A. and Ali G.M., "On the Mechanical Properties of $\gamma^{\prime}$-Hardened Ni-10\% CO Alloy", Proc. of the Second International Conf. on Technology for Development Organised by G.O.F.I, Cairo, pp.86-96, May (1982).

7. Davies P.W. and Williams K.R, "The Tertiary Creep and Fracture of Oxygen-Free High Conductivity Copper", J. Inst. Met., 97, 337-342, (1969).

8. Davies P.W. and Williams K.R., "Recovery Measurements during Tertiary Creep of a-Iron", Acta Met., 17, 897-903, (1969).

9. Silcock J.M., "Analyses of Tertiary Creep", Scripta Met., 16, 907-910, (1982) .

10. Abdou M.A. and Buchmayr B., "Tertiary Creep and Fracture of $\gamma^{\prime}$-Strengthened Nickel Base alloy", Current Advances in Mechanical Design and Production 111, Proceedings of the Third Cairo Univ. MDP Conf., Pergamon Press, (1985). :11. Robotnov Y.N., "Creep Problems in Structural Members", North Holland, :
Amsterdam (1969).

\section{NOMENCLATURE}

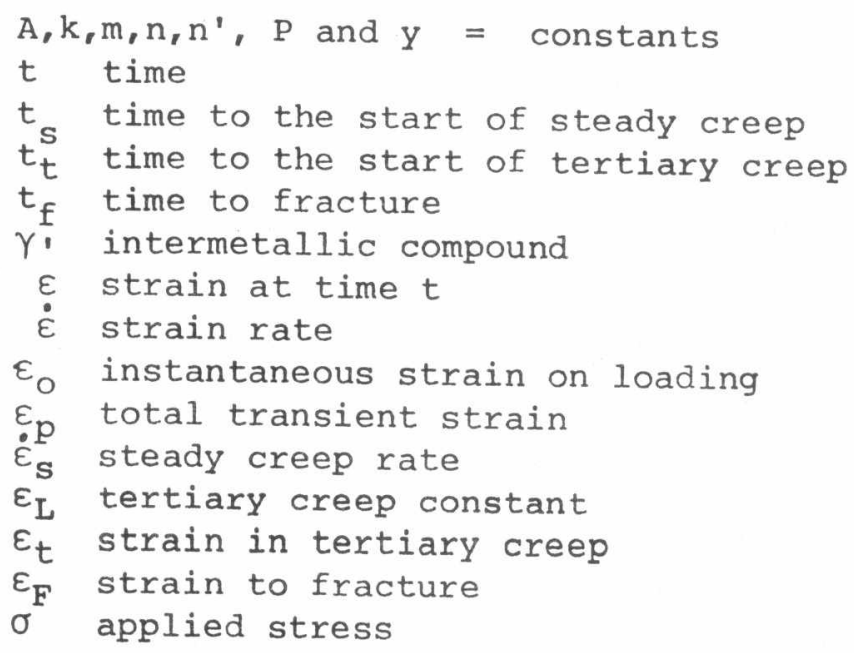




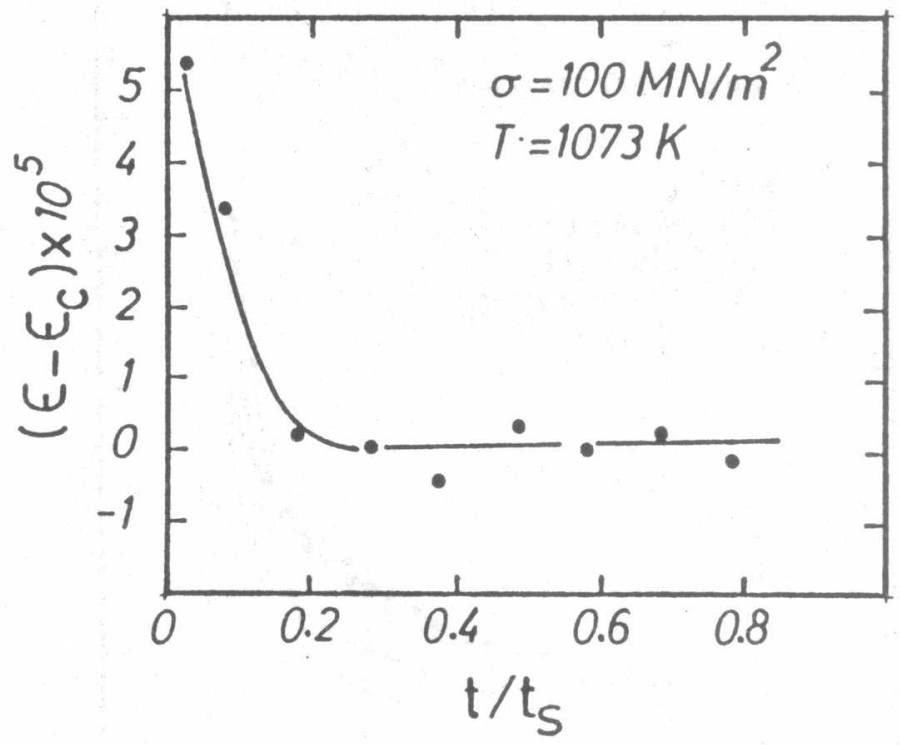

Fig.1 Representation of the difference between the measured creep $\operatorname{strain}(\varepsilon)$ and the calculated value $\left(\varepsilon_{C}\right)$ with time during transient creep for Ni-7.138 AL alloy tested at $100 \mathrm{MPa}$.

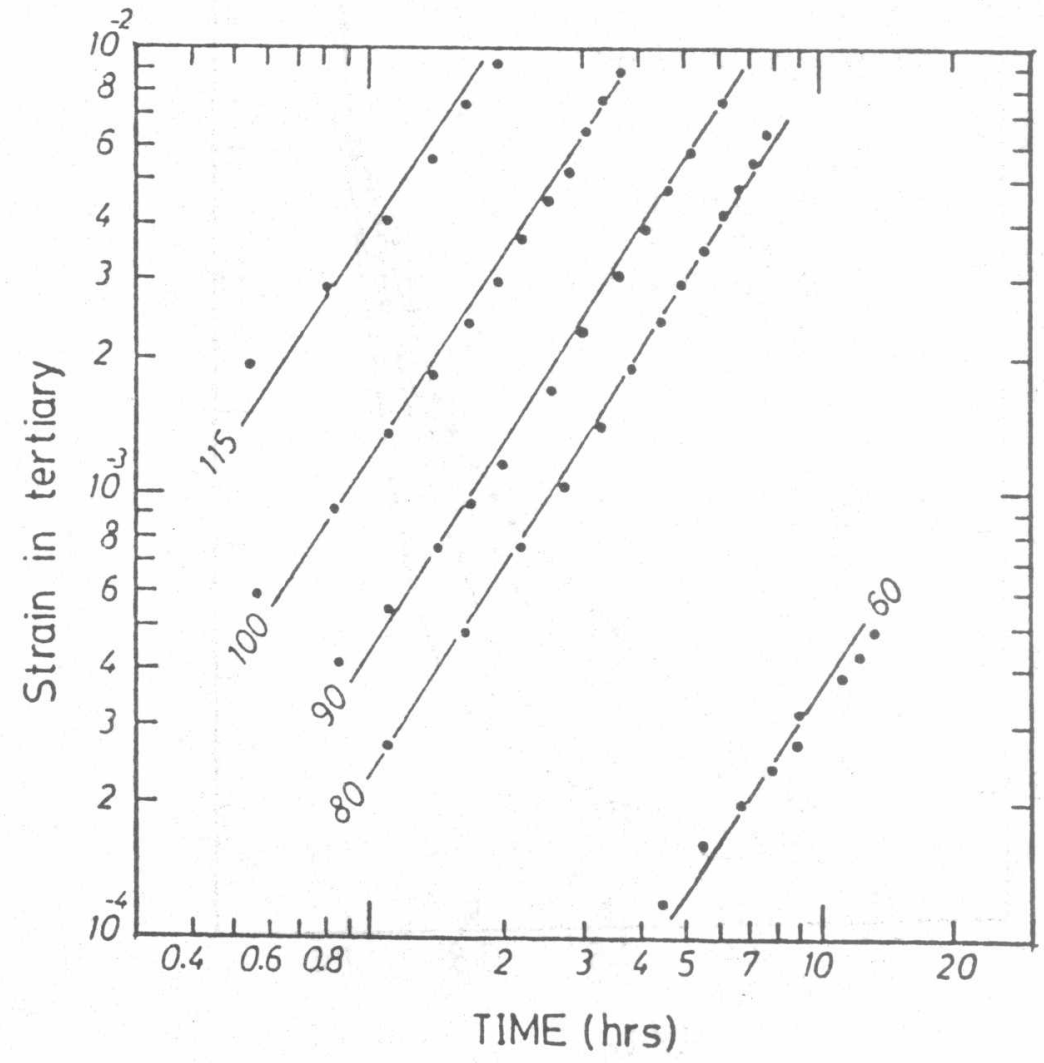

Fig.2 Typicial strain-time relationships for the early stages of tertiary creep 


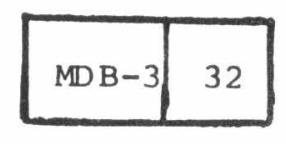

SECOND A.M.E. CONFIRENCE

6 - 8 May 1986 , Cairo

$r$

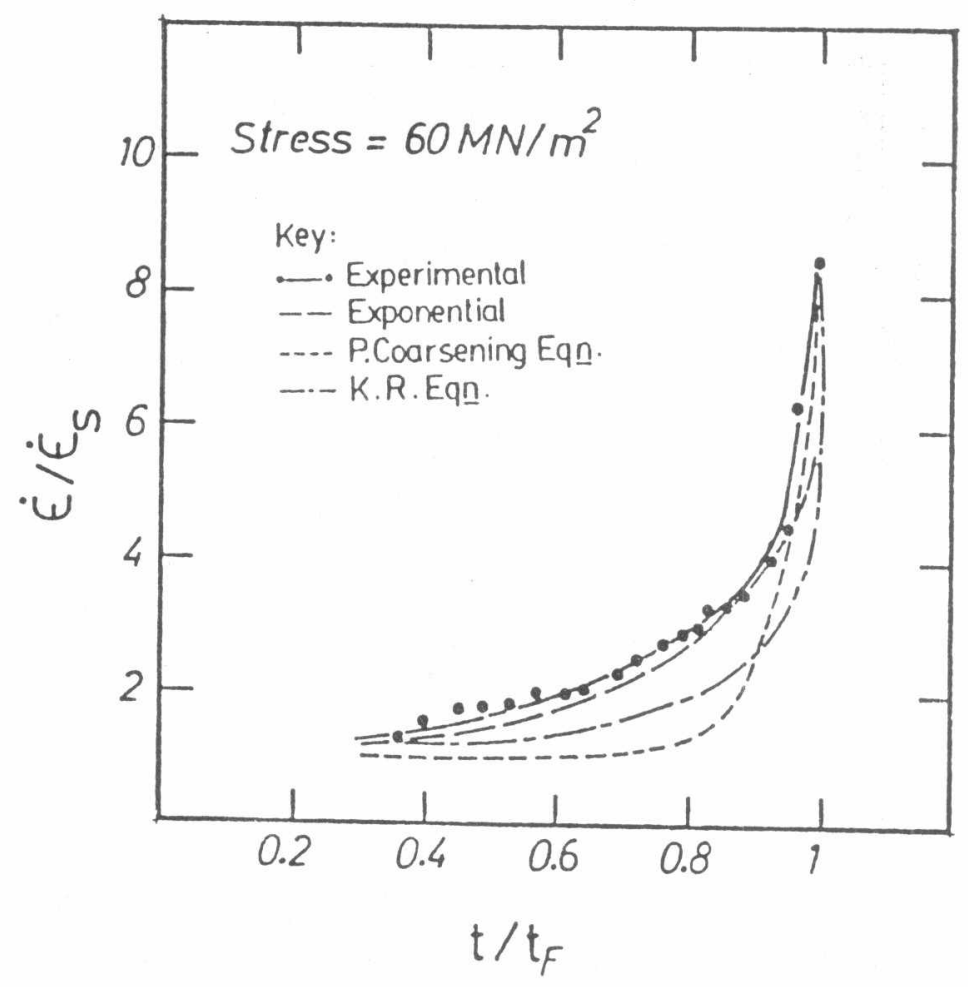

(a)

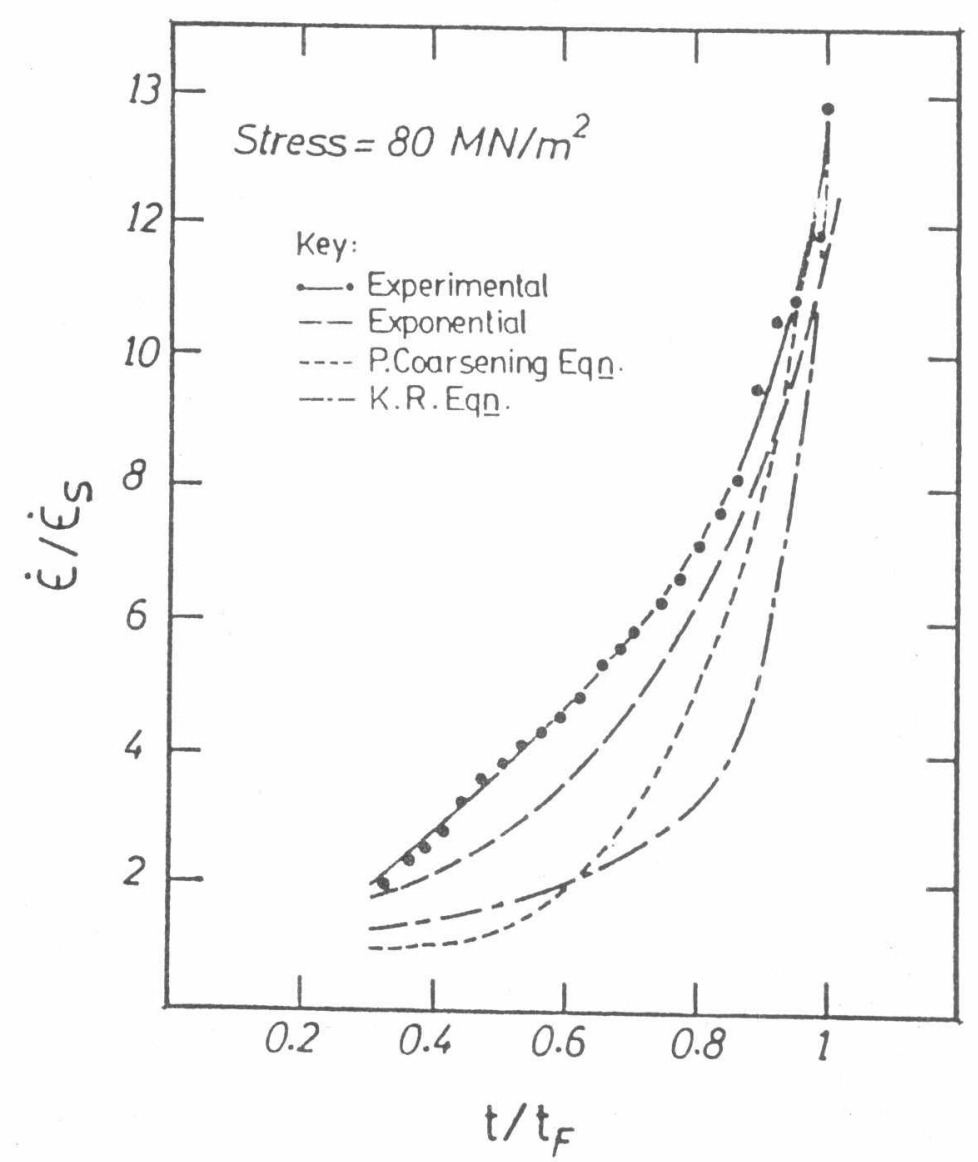

(b)

Fig.3 Creep rate changes during tertiary, 


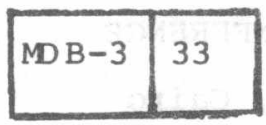

$r$

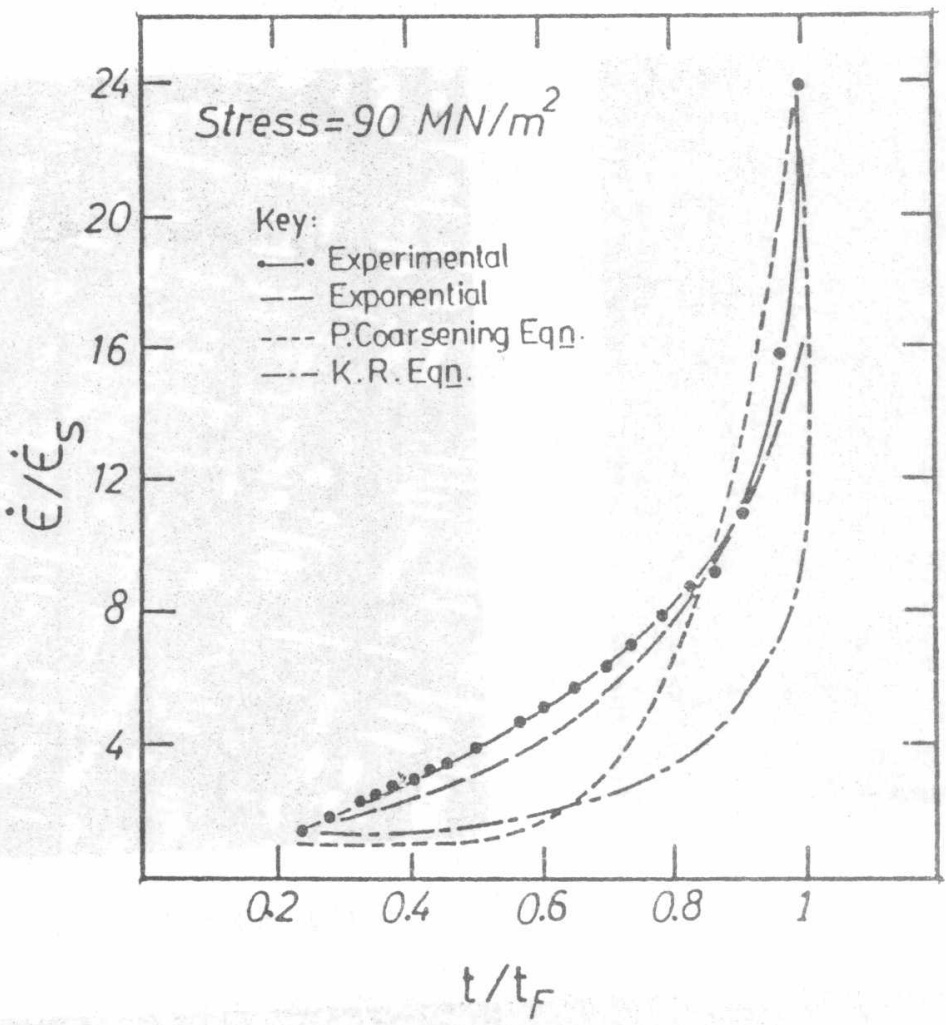

(c)

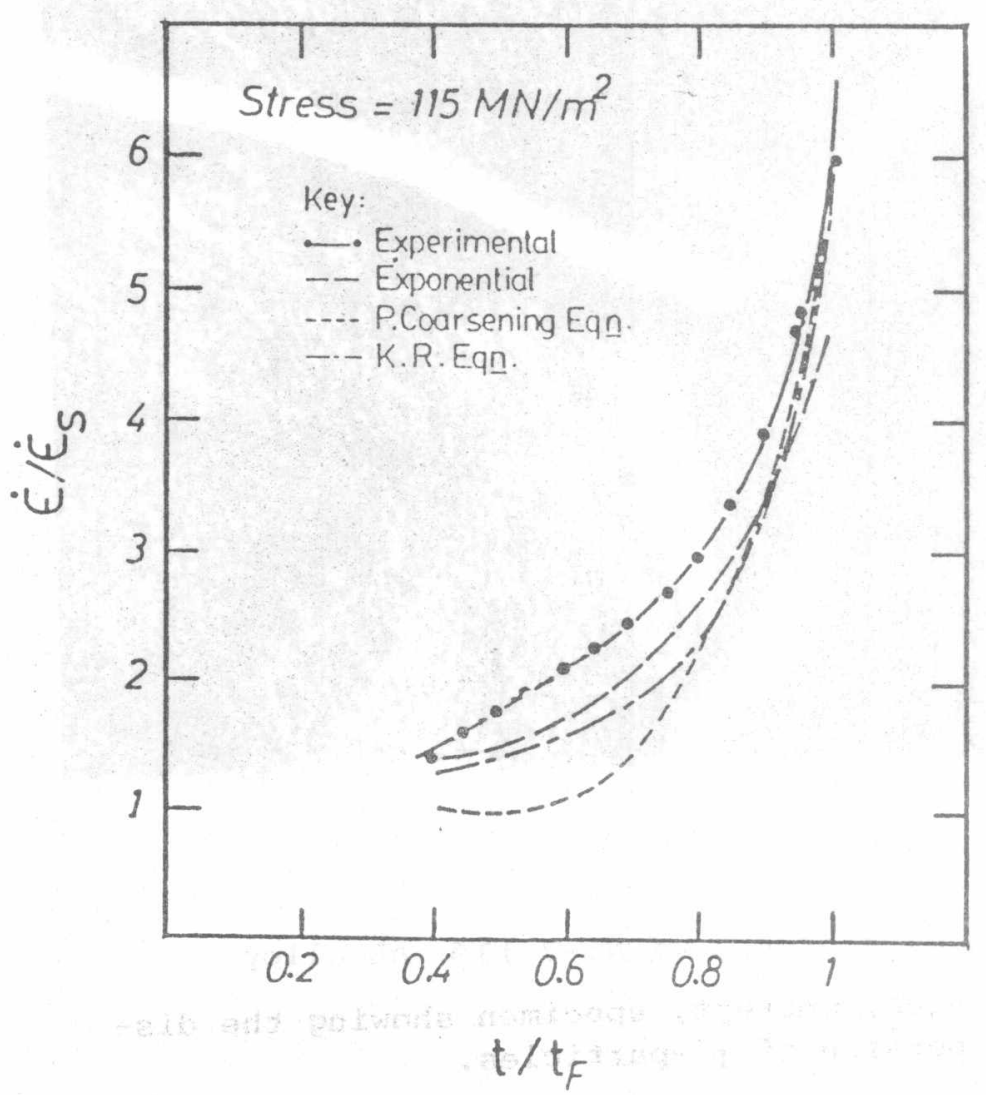

(d)

Fig.3 Creep rate changes during tertiary, 


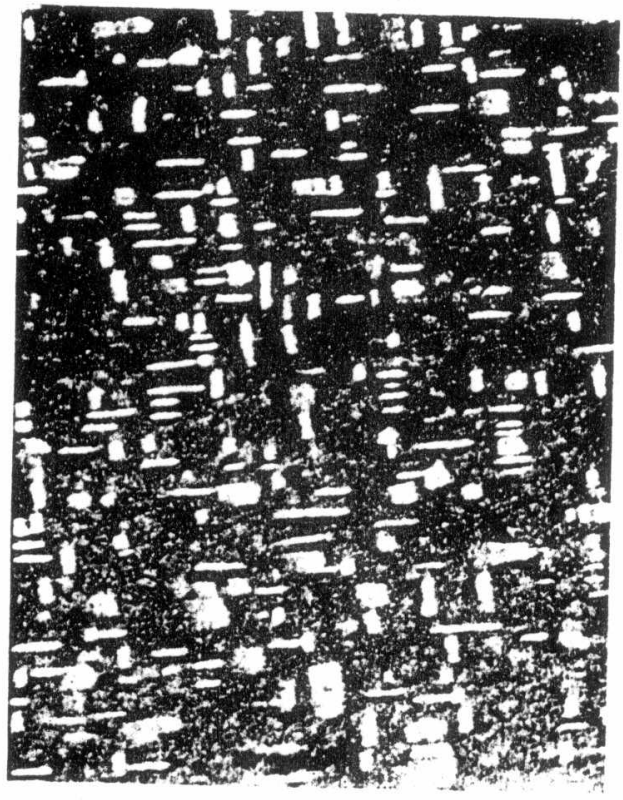

(a) $5000 \mathrm{x}$

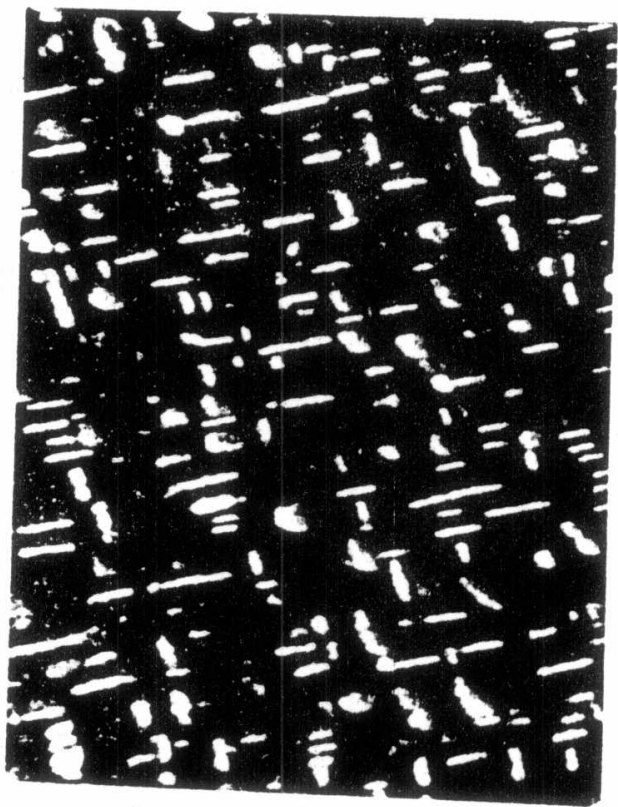

(b) $5000 x$

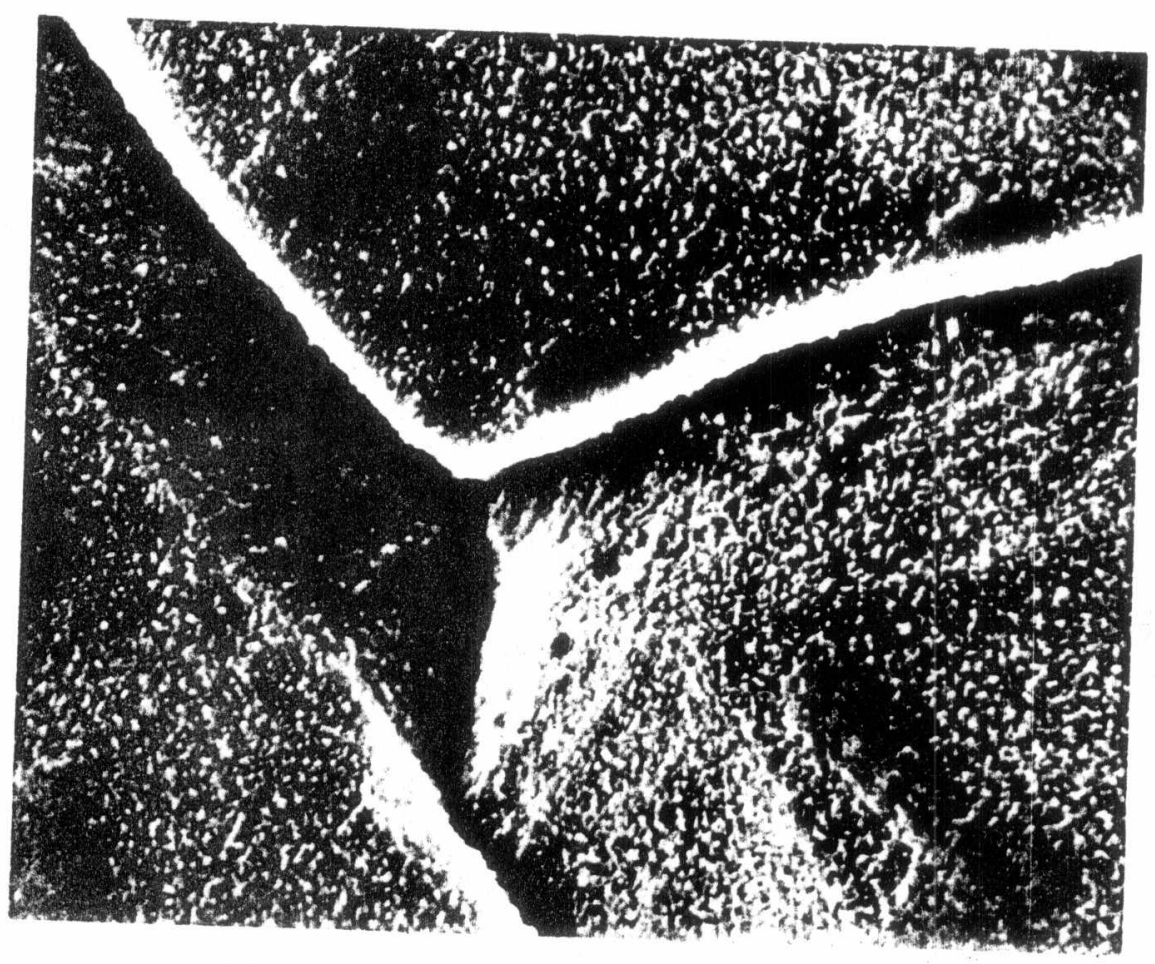

(c) $2000 \mathrm{x}$

Fig.4 SEM micrographs of $\mathrm{Ni}-7.13 \%$ AL alloy
a) Aged, uncrept, specimen showing the dis- persion of $\gamma^{\prime}$-particles.
b) Creep tested specimen at $90 \mathrm{MPa}$.
c) Fractured surfaces of specimen crept at $90 \mathrm{MPa}$. 